\title{
Recent hip fracture trends in Sweden and Denmark with age-period-cohort effects
}

\author{
B. E. Rosengren ${ }^{1,2}$ • J. Björk ${ }^{3}$ C C. Cooper ${ }^{4}$ B. Abrahamsen ${ }^{2,5}$
}

Received: 11 May 2016 / Accepted: 6 September 2016 / Published online: 19 September 2016

(C) The Author(s) 2016. This article is published with open access at Springerlink.com

\begin{abstract}
Summary This study used nationwide hip fracture data from Denmark and Sweden during 1987-2010 to examine effects of (birth) cohort and period. We found that time trends, cohort, and period effects were different in the two countries. Results also indicated that hip fracture rates may increase in the not so far future.

Introduction The reasons for the downturn in hip fracture rates remain largely unclear but circumstances earlier in life seem important.

Methods We ascertained hip fractures in the populations $\geq 50$ years in Denmark and Sweden in national discharge registers. Country- and sex-specific age-period-cohort (APC) effects during 1987-2010 were evaluated by log-likelihood estimates in Poisson regression models presented as incidence rate ratios (IRR).
\end{abstract}

Electronic supplementary material The online version of this article (doi:10.1007/s00198-016-3768-3) contains supplementary material, which is available to authorized users.

B. E. Rosengren

bjorn.rosengren@med.lu.se

1 Clinical and Molecular Research Unit, Departments of Orthopedics and Clinical Sciences, Skåne University Hospital Malmö, Lund University, 20502 Malmö, Sweden

2 Odense Patient Data Explorative Network, Institute of Clinical Research, University of Southern Denmark, 5000 Odense, Denmark

3 Department of Occupational and Environmental Medicine, Lund University, Lund, Sweden

4 MRC Lifecourse Epidemiology Unit, University of Southampton, Southampton SO16 6YD, UK

5 Department of Medicine, Holbæk Hospital, 4300 Holbæk, Denmark
Results There were 399,596 hip fractures in SE and 248,773 in DK. Age-standardized hip fracture rate was stable in SE men but decreased in SE women and in DK. Combined period + cohort effects were generally stronger in SE than DK and in women than men. IRR per period ranged from 1.05 to 1.30 in SE and 0.95 to 1.21 in DK. IRR per birth cohort ranged from 1.07 to 3.13 in SE and 0.77 to 1.67 in DK. Relative period effects decreased with successive period in SE and described a convex curve in DK. Relative cohort effects increased with successive birth cohort in both countries but with lower risks for DK women and men and SE women born around the 1930s (age 75-86 years today and responsible for most hip fractures) partly explaining the recent downturn. Men and women born thereafter however seem to have a higher hip fracture risk, and we expect a reversal of the present decline in rates, with increasing hip fracture rates in both Denmark and Sweden during the upcoming decade.

Conclusions Time trends, cohort, and period effects were different in SE and DK. This may reflect differences in general health as evident in known differences in life expectancy, healthcare organization, and prevention such as use of antiosteoporosis drugs. Analyses indicate that hip fracture rates may increase in the not so far future.

Keywords Age-period-cohort · Hip fracture - Men · Trends · Women

\section{Introduction}

Hip fractures due to osteoporosis are overwhelmingly a disease of the industrial world, with fracture rates increasing proportionally with gross domestic income and education level across countries and with increasing rates and increasing 
female-to-male ratio as nations gradually adopt a Western, industrial lifestyle [1].

During the past one or two decades, however, a break in the increasing trend has been seen in most parts of the Western world [2] including Scandinavia [3-6] with stable - or even decreasing - hip fracture rates.

The many studies highlighting this downturn have not been followed by an equal interest in identifying the responsible mechanism, and many have been satisfied by the coinciding advent and rise of antiresorptive osteoporosis treatment [7], a notion not supported by other studies $[6,8]$.

The reasons for the recent changes remain largely unclear, and while current efforts are important (such as antiresorptive osteoporosis treatment), also, circumstances earlier in life seem essential as evident in previous studies investigating differences in hip fracture risk between birth cohorts [7, 9-13]. The origin of the changes in hip fractures is particularly challenging to unravel because of their peak incidence late in life and the consequent need for explanatory models to access information about societal, and preferably individual, exposures as early as five to eight decades earlier [14], a point in time where national health and lifestyle surveys were few and far apart.

Denmark (DK) and Sweden (SE) are neighboring northern European countries with very high rates of fragility fractures [15]. We have previously examined hip fracture incidence separately for both countries $[5,6]$ but now set out to examine more recent incidence and time trends as well as age-periodcohort effects in the two countries using identical methodology.

\section{Methods}

We studied the entire populations aged $\geq 50$ years from year 1980 to 2010 in DK and 1987 to 2011 in SE in discharge data from the registries of the National Board of Health and Welfare in each country. Each year, patients with an acute hip fracture were identified using the diagnosis code for proximal femoral fracture as well as a relevant surgical procedural code (Online Resource 1). For estimation of the population at risk, we acquired annual population data for men and women aged $\geq 50$ years in 1-year age bands for the entire observation period from Statistics Sweden and Statistics Denmark (government authorities for official statistics including all inhabitants in each country).

During the study periods, major changes in the population $\geq 50$ years were evident. In Denmark, the annual population $\geq 50$ years was about 1.6 million in between 1980 and 1987 rising to 2 million in 2010 (53 million person years) and in Sweden from 2.8 to 3.5 million from 1987 to 2011 (79 million person years). The expected survival at age 50 also increased in both countries. Hence, residual life expectancy increased from 32 to 35 years in women and from 28 to 31 years in men in Sweden (Statistics Sweden) and from 30 to 33 (women) and 25 to 29 (men) in Denmark (Statistics Denmark). The age distribution in both women and men age $\geq 50$ years in both countries underwent marked changes during the study period (Online Resource 2).

We used national inpatient data for individuals aged $\geq 50$ years in Denmark during 1980-2010 and in Sweden during 1987-2011 to examine annual numbers and incidence rates of hip fractures. During the years where data were available for both countries, i.e., 1987-2010, we evaluated ageperiod-cohort effects by log-likelihood estimates in Poisson regression models. This approach was introduced by Clayton and Shifflers [16,17] and Hollford [18] and has been described in detail previously [12]. The models were fitted to gender- and nation-specific hip fracture data of Swedish and Danish men and women age 50-97 years 1987 to 2010 using 4-year age and period intervals and 8-year intervals for cohort (starting at every fourth year and hence overlapping), yielding 12 different age groups, 6 time periods, and 17 birth cohorts.

The rationale for using 8-year (birth) cohort classes while 4-year classes are used for age and period is to make sure that all persons that belong to a certain age class during a particular period at the same time also belong to the same cohort class. To make this happen, the length of the cohort class must be twice the length of the age and period classes (please see Online Resource 3 and Table 2 (including the footnote) for further explanation). By decomposing the effect parameters of the general APC model, it can be shown that the (log) linear trends ("drifts") of the three components age, period, and cohort cannot be separated. This means for example that linear trends over calendar time cannot be unambiguously distinguished from linear trends over birth cohort, i.e., period effects are inherent in cohort effects and vice versa. However, deviations from the underlying linear trends ("curvatures") can be estimated separately for period and cohort effects (i.e., relative differences between different cohorts or different periods) [18, 19]. We set the cohort effects of the two youngest birth cohorts (1949-1956 and 1953-1960) to zero in order to make estimation of the APC model parameters possible. We limited the APC analysis to age 97 years to avoid statistical instability as available population statistics were aggregated from age 100 years rendering population data for older age strata (98101 years and older) unreliable.

Age adjustment was done by direct standardization with the mean total population of both countries during 1987 2010 as reference, time-trend analysis by linear regression, and identification of breakpoints in linear trends by joinpoint analysis (Joinpoint Regression Program, Version 4.0.4. May 2013; Statistical Research and Applications Branch, National Cancer Institute, USA). The study was approved by Statistics Denmark (project reference 703857) and the ethics committee at Lund University, Sweden (2012/394). 


\section{Results}

During the examined years, there were 399,596 hip fractures in SE (72 \% in women) and 248,773 in DK (74\% in women). The overall hip fracture rates $(\geq 50$ years $)$ per 10,000 person years during 1987-2010 (where data were available for both countries) were 55 in SE (32 in men and 74 in women) and 49 in DK (28 in men, 68 in women). As DK rates 1995 (low) and 1996 (high) stood out compared to other DK years, coinciding with the change from ICD-8 to ICD-10 which may have led to recoding in the transition years, we henceforth used the crude 2-year incidence 1995-1996 (in 1-year age classes) to estimate the annual incidence for each of these 2 years and to estimate annual numbers.

Generally, the join-point analysis showed that the overall annual number of hip fractures ( $\geq 50$ years) increased in both men and women in both SE and DK until the mid-1990s whereafter the numbers decreased in both Swedish and Danish women $(-0.5 \%[95 \% \mathrm{CI}-0.7,-0.2]$ respective $-1.8 \%[-2.3,-1.3])$, were stable in Danish men $(+0.1 \%[-0.3,0.6])$, and increased in Swedish men $(+1.3 \%$ per year $[0.9,1.7])$; details are presented in Fig. 1 and Online Resource 4.

The overall annual age-standardized rate ( $\geq 50$ years) for Swedish men increased from 1987 to 1996 followed by a decrease until 2000 whereafter the rate was stable $(-0.4 \%$ [95\% CI $-0.8,0.1])$. For Swedish women, the rate was stable until 1999 whereafter a decrease $(-1.3 \%[-1.6,-1.0])$ was evident. In DK, rates increased in both men and women until 2001 respective 1997 whereafter decreases were evident in both genders $(-1.8 \%[-2.4,-1.2]$ respective $-3.1 \%[-4.0$, $-2.1]$ ); details are presented in Fig. 1 and Table 1.

Age-, period-, and cohort-specific hip fracture data are presented in Table 2. Birth cohorts (per 8-year stratum) can be followed diagonally from left to right in the table. As an example, individuals aged 50-53 years old during the first period (1987-1990) were born during 1933-1940 (top left column of the table) and are shaded in the table. The same individuals were during the next period (1991-1994) 54-57 years old and can be found one row down and one column to the right from the top left column. Relevant model building details are presented in Online Resource 5 where it can be seen that the full APC model provided the best fit for both men and
Fig. 1 Annual age-standardized hip fracture rate (per 10,000) and number of hip fractures in Danish and Swedish men and women (Denmark year 1980 to 2010 and Sweden 1987 to 2011). By direct standardization with the mean total population of both countries during the observation years 1987-2010 as reference
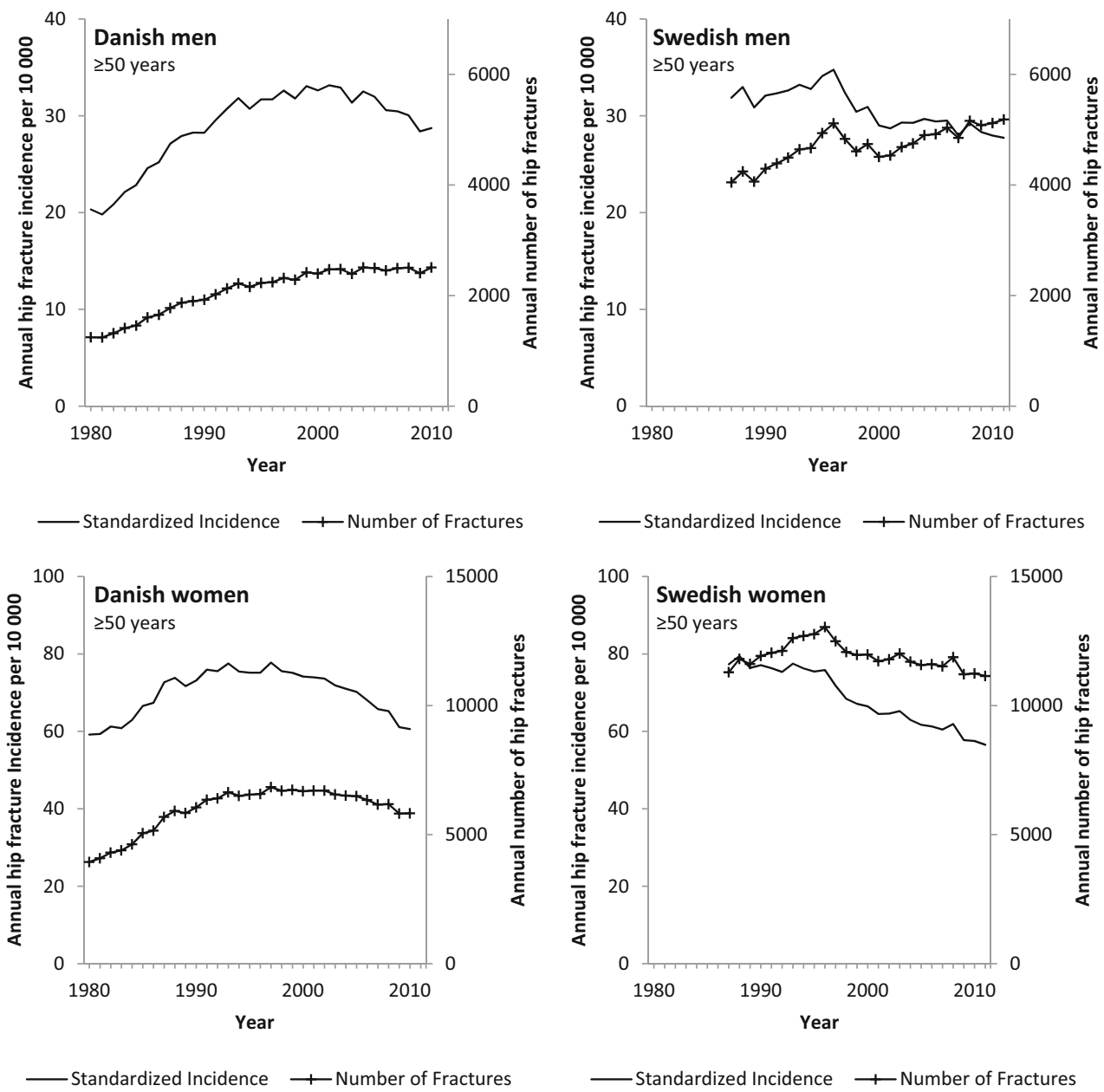
Table 1 Time trends in annual age-standardized hip fracture rate in Sweden and Denmark presented as annual percent (\%) change between breakpoints

\begin{tabular}{|c|c|c|c|c|c|c|}
\hline \multirow[t]{2}{*}{ Age span } & \multicolumn{3}{|l|}{ Men } & \multicolumn{3}{|l|}{ Women } \\
\hline & Breakpoint & Period & Annual percent change & Breakpoint & Period & Annual percent change \\
\hline \multicolumn{7}{|l|}{ Sweden } \\
\hline \multirow[t]{3}{*}{$\geq 50$} & & 1987-1996 & $+0.8^{*}(0.2,1.4)$ & & 1987-1996 & $-0.4(-0.8,0.0)$ \\
\hline & 1996 & $1996-2000$ & $-3.4^{*}(-6.5,-0.2)$ & 1996 & 1996-1999 & $-3.7(-8.1,0.8)$ \\
\hline & 2000 & $2000-2011$ & $-0.4(-0.8,0.1)$ & 1999 & 1999-2011 & $-1.3^{*}(-1.6,-1.0)$ \\
\hline \multirow[t]{4}{*}{$50-79$} & & 1987-1996 & $+0.4(-0.2,0.9)$ & & $1987-1993$ & $-0.8(-1.9,0.3)$ \\
\hline & 1996 & $1996-2001$ & $-3.5^{*}(-5.3,-1.8)$ & 1993 & 1993-2011 & $-2.1^{*}(-2.3,-1.9)$ \\
\hline & 2001 & 2001-2004 & $+1.2(-4.5,7.1)$ & & & \\
\hline & 2004 & 2004-2011 & $-1.5^{*}(-2.2,-0.7)$ & & & \\
\hline \multirow[t]{3}{*}{$\geq 80$} & & 1987-1996 & $+1.2^{*}(0.5,1.9)$ & & 1987-1996 & $-0.1(-0.5,0.4)$ \\
\hline & 1996 & 1996-1999 & $-4.3(-11.0,2.8)$ & 1996 & 1996-1999 & $-3.6(-8.6,1.7)$ \\
\hline & 1999 & 1999-2011 & $-0.1(-0.5,0.3)$ & 1999 & 1999-2011 & $-1.1^{*}(-1.4,-0.8)$ \\
\hline \multicolumn{7}{|l|}{ Denmark } \\
\hline \multirow[t]{5}{*}{$\geq 50$} & & 1980-1989 & $+4.5^{*}(3.9,5.2)$ & & 1980-1984 & $+1.5^{*}(0.1,3.0)$ \\
\hline & 1989 & 1989-2001 & $+1.2^{*}(0.8,1.7)$ & 1984 & 1984-1987 & $+5.1^{*}(0.4,9.9)$ \\
\hline & 2001 & $2001-2010$ & $-1.8^{*}(-2.4,-1.2)$ & 1987 & 1987-1997 & $+0.6^{*}(0.2,1.0)$ \\
\hline & & & & 1997 & $1997-2005$ & $-1.1^{*}(-1.7,-0.5)$ \\
\hline & & & & 2005 & $2005-2010$ & $-3.1^{*}(-4,-2.1)$ \\
\hline \multirow[t]{3}{*}{$50-79$} & & $1980-1988$ & $+3.8^{*}(2.6,4.9)$ & & 1980-1991 & $+2.6^{*}(2.0,3.2)$ \\
\hline & 1988 & $1988-2001$ & $+0.8^{*}(0.2,1.5)$ & 1991 & $1991-2005$ & $-1.0^{*}(-1.4,-0.5)$ \\
\hline & 2001 & 2001-2010 & $-1.4^{*}(-2.3,-0.5)$ & 2005 & 2005-2010 & $-3.7^{*}(-5.7,-1.8)$ \\
\hline \multirow[t]{3}{*}{$\geq 80$} & & 1980-1991 & $+5.2^{*}(4.5,5.8)$ & & 1980-1991 & $+2.5^{*}(2.1,3.0)$ \\
\hline & 1991 & $1991-2001$ & $+1.3^{*}(0.4,2.1)$ & 1991 & $1991-2002$ & $+0.0(-0.5,0.5)$ \\
\hline & 2001 & $2001-2010$ & $-1.9^{*}(-2.8,-1.1)$ & 2002 & $2002-2010$ & $-2.4^{*}(-3.1,-1.7)$ \\
\hline
\end{tabular}

*A statistically significant change

women in both SE and DK (by comparing the deviance between adjacent modeling steps).

Results from AC- and AP-models are presented in Table 3. Note that both models estimate the sum of period and cohort effects. When stratified by cohort (in the AC models), these combined effects were noticeably stronger in SE than DK and in women than men.

Incidence rate ratios (IRR) per period in the AP models ranged from 1.05 to 1.30 in Swedish women, 1.03 to 1.15 in Swedish men, 1.11 to 1.21 in Danish women, and 0.95 to 1.11 in Danish men.

The corresponding IRR per birth cohort in the AC models ranged from 1.16 to 3.13 in Swedish women, 1.07 to 1.61 in Swedish men, 1.06 to 1.67 in Danish women, and 0.77 to 1.14 in Danish men.

In the APC models, relative period effects (actual relative differences between periods without any interfering cohort effects) decreased with successive period for men and women in SE and described a convex curve for both men and women in DK with higher than expected risk in the periods in the middle of the examination years (Fig. 2).

Relative cohort effects (actual relative differences between cohorts without any interfering period effects) increased with successive birth cohort for both genders in both countries but with markedly lower relative risks for Danish women born in 1929-1952 and Danish men born in 1925-1944, and lower relative risks for Swedish men born in 1933-1948 and Swedish women born in 1933-1944 (Fig. 2).

\section{Discussion}

In this study of nationwide hip fracture data in Sweden and Denmark during up to 31 years, decreasing or stable age-standardized rates were evident in both genders and in both countries during the most recent decade. This was accompanied by a decreasing annual number of hip fractures in women (both SE and DK), stable numbers in 
Table 2 Hip fracture rate per 4-year period (from year 1987 to 2010) and 4-year age stratum (from age 50 to 97 years) in Sweden and Denmark. Birth cohorts (per 8-year stratum) can be followed diagonally from left to right in the table

\begin{tabular}{|c|c|c|c|c|c|c|c|c|c|c|c|c|}
\hline & \multicolumn{6}{|c|}{$\begin{array}{l}\text { Sweden } \\
\text { Hip fracture rate (per 10,000) } \\
\text { per 4-year period }\end{array}$} & \multicolumn{6}{|c|}{$\begin{array}{l}\text { Denmark } \\
\text { Hip fracture rate (per 10,000) } \\
\text { per 4-year period }\end{array}$} \\
\hline & $\begin{array}{l}1987- \\
1990\end{array}$ & $\begin{array}{l}1991- \\
1994 \\
\end{array}$ & $\begin{array}{l}1995- \\
1998\end{array}$ & $\begin{array}{l}1999- \\
2002\end{array}$ & $\begin{array}{l}2003- \\
2006\end{array}$ & $\begin{array}{l}2007- \\
2010\end{array}$ & $\begin{array}{l}1987- \\
1990\end{array}$ & $\begin{array}{l}1991- \\
1994\end{array}$ & $\begin{array}{l}1995- \\
1998\end{array}$ & $\begin{array}{l}1999- \\
2002\end{array}$ & $\begin{array}{l}2003- \\
2006\end{array}$ & $\begin{array}{l}2007- \\
2010\end{array}$ \\
\hline \multicolumn{13}{|l|}{ Men } \\
\hline $50-53$ & 4 & 4 & 3 & 3 & 3 & 3 & 3 & 4 & 4 & 4 & 5 & 4 \\
\hline $54-57$ & 5 & 5 & 5 & 4 & 5 & 4 & 5 & 5 & 5 & 6 & 7 & 7 \\
\hline $58-61$ & 8 & 8 & 7 & 6 & 7 & 6 & 7 & 8 & 7 & 9 & 8 & 9 \\
\hline $62-65$ & 12 & 12 & 12 & 10 & 10 & 10 & 12 & 11 & 12 & 12 & 11 & 12 \\
\hline $66-69$ & 18 & 19 & 19 & 16 & 16 & 14 & 18 & 17 & 17 & 20 & 19 & 17 \\
\hline $70-73$ & 29 & 31 & 31 & 27 & 27 & 24 & 28 & 32 & 30 & 28 & 28 & 27 \\
\hline $74-77$ & 53 & 51 & 53 & 48 & 46 & 43 & 48 & 51 & 55 & 54 & 46 & 45 \\
\hline $78-81$ & 86 & 92 & 92 & 81 & 82 & 78 & 71 & 84 & 86 & 88 & 85 & 70 \\
\hline $82-85$ & 146 & 146 & 156 & 134 & 137 & 132 & 116 & 133 & 142 & 144 & 143 & 130 \\
\hline $86-89$ & 219 & 225 & 230 & 214 & 213 & 212 & 176 & 204 & 213 & 219 & 217 & 203 \\
\hline $90-93$ & 319 & 326 & 324 & 309 & 307 & 305 & 244 & 265 & 307 & 307 & 297 & 287 \\
\hline $94-97$ & 369 & 437 & 397 & 400 & 392 & 422 & 376 & 379 & 400 & 428 & 339 & 349 \\
\hline \multicolumn{13}{|c|}{ Women } \\
\hline $50-53$ & 4 & 3 & 3 & 3 & 3 & 2 & 5 & 4 & 4 & 4 & 4 & 4 \\
\hline $54-57$ & 8 & 6 & 6 & 5 & 5 & 4 & 9 & 7 & 7 & 6 & 6 & 7 \\
\hline 58-61 & 13 & 12 & 10 & 8 & 8 & 8 & 15 & 13 & 12 & 9 & 11 & 11 \\
\hline $62-65$ & 19 & 19 & 16 & 13 & 13 & 13 & 21 & 21 & 19 & 17 & 16 & 16 \\
\hline $66-69$ & 31 & 30 & 28 & 26 & 24 & 20 & 34 & 35 & 35 & 30 & 30 & 24 \\
\hline $70-73$ & 54 & 53 & 51 & 45 & 45 & 38 & 55 & 57 & 59 & 55 & 51 & 43 \\
\hline 74-77 & 98 & 96 & 88 & 82 & 76 & 72 & 91 & 98 & 97 & 95 & 90 & 77 \\
\hline $78-81$ & 167 & 169 & 156 & 139 & 135 & 123 & 149 & 155 & 157 & 159 & 149 & 131 \\
\hline $82-85$ & 266 & 265 & 260 & 228 & 213 & 210 & 235 & 246 & 249 & 247 & 227 & 213 \\
\hline $86-89$ & 381 & 371 & 364 & 335 & 319 & 304 & 343 & 361 & 367 & 361 & 336 & 304 \\
\hline 90-93 & 455 & 461 & 450 & 421 & 415 & 394 & 418 & 469 & 454 & 455 & 446 & 400 \\
\hline $94-97$ & 485 & 488 & 465 & 444 & 445 & 468 & 495 & 548 & 537 & 525 & 509 & 472 \\
\hline
\end{tabular}

In the year 1987, individuals who were 50 years old were born in 1937 (or 1936 if they not had their 51st birthday yet) and individuals who were 53 years old were born in 1934 (or 1933 if they had not had their 54th birthday yet). In the year 1990, individuals who were 50 years old were born in 1940 (or 1939 if they not had their 51st birthday yet) and individuals who were 53 years old were born in 1937 (or 1936 if they had not had their 54th birthday yet). Consequently, individuals who were 50-53 years old during the period 1987-1990 were born between 1933 and 1940 and are located at the top left column during 1987-1990. This birth cohort can be followed diagonally in the table and is shaded for clarity

Danish men, and increasing numbers in SE men. The combined period and cohort effects were generally stronger in SE than DK and in women than men. Relative cohort effects (actual relative differences between cohorts without any interfering period effects) increased with successive birth cohort for both genders in both countries but with markedly lower relative risks for Danish women born in 1929-1952 and Danish men born in 1925-1944 and 
Table 3 Birth cohort effects from age-cohort (AC) models and calendar period effects from age-period (AP) models presented as IRR (incidence rate ratios) with $95 \%$ confidence intervals in comparison with the respective reference (REF) birth or period cohort. Note that period effects are inherent in the cohort effects of the AC model and vice versa

\begin{tabular}{|c|c|c|c|c|}
\hline & $\begin{array}{l}\text { Swedish men } \\
\text { IRR }(95 \% \text { CI) }\end{array}$ & $\begin{array}{l}\text { Danish men } \\
\text { IRR (95 \% CI) }\end{array}$ & $\begin{array}{l}\text { Swedish women } \\
\text { IRR ( } 95 \% \text { CI) }\end{array}$ & $\begin{array}{l}\text { Danish women } \\
\text { IRR (95\% CI) }\end{array}$ \\
\hline \multicolumn{5}{|l|}{ Birth cohort } \\
\hline \multicolumn{5}{|c|}{ Birth cohort effects from age-cohort (AC) models } \\
\hline 1889-1896 & $1.42 *(1.05$ to 1.91$)$ & $0.85(0.56$ to 1.31$)$ & $3.13 *(2.30$ to 4.27$)$ & $1.59 *(1.03$ to 2.45$)$ \\
\hline $1893-1900$ & $1.61 *(1.27$ to 2.04$)$ & $0.77(0.55$ to 1.08$)$ & $3.10 *(2.31$ to 4.15$)$ & $1.62 *(1.09$ to 2.40$)$ \\
\hline $1897-1904$ & $1.56^{*}(1.24$ to 1.96$)$ & $0.79(0.58$ to 1.08$)$ & $3.10 *(2.32$ to 4.14$)$ & $1.67 *(1.13$ to 2.47$)$ \\
\hline 1901-1908 & $1.57 *(1.26$ to 1.97$)$ & $0.86(0.63$ to 1.16$)$ & $3.00 *(2.24$ to 4.00$)$ & $1.66 *(1.13$ to 2.44$)$ \\
\hline 1905-1912 & $1.55^{*}(1.24$ to 1.94$)$ & $0.87(0.65$ to 1.18$)$ & $2.92 *(2.19$ to 3.90$)$ & $1.66 *(1.13$ to 2.44$)$ \\
\hline $1909-1916$ & $1.58 *(1.26$ to 1.97$)$ & $0.92(0.69$ to 1.24$)$ & $2.84 *(2.13$ to 3.79$)$ & $1.63 *(1.11$ to 2.40$)$ \\
\hline $1913-1920$ & $1.49 *(1.19$ to 1.86$)$ & $0.93(0.69$ to 1.25$)$ & $2.62 *(1.97$ to 3.50$)$ & $1.59 *(1.08$ to 2.34$)$ \\
\hline $1917-1924$ & $1.46 *(1.17$ to 1.83$)$ & $0.95(0.71$ to 1.28$)$ & $2.43 *(1.82$ to 3.24$)$ & $1.54 *(1.05$ to 2.26$)$ \\
\hline $1921-1928$ & $1.43 *(1.14$ to 1.78$)$ & $0.92(0.68$ to 1.23$)$ & $2.33 *(1.75$ to 3.11$)$ & $1.52 *(1.03$ to 2.23$)$ \\
\hline $1925-1932$ & $1.35 *(1.09$ to 1.69$)$ & $0.82(0.61$ to 1.10$)$ & $2.14 *(1.61$ to 2.86$)$ & 1.45 (0.99 to 2.12$)$ \\
\hline 1929-1936 & $1.28^{*}(1.02$ to 1.60$)$ & $0.87(0.65$ to 1.17$)$ & $2.04 *$ (1.53 to 2.72$)$ & $1.32(0.90$ to 1.93$)$ \\
\hline 1933-1940 & $1.20(0.96$ to 1.50$)$ & $0.87(0.65$ to 1.16$)$ & $1.74 *(1.31$ to 2.32$)$ & $1.20(0.82$ to 1.75$)$ \\
\hline 1937-1944 & 1.11 ( 0.89 to 1.38$)$ & $0.86(0.64$ to 1.14$)$ & $1.54 *(1.15$ to 2.06$)$ & $1.06(0.72$ to 1.56$)$ \\
\hline 1941-1948 & 1.10 (0.88 to 1.37$)$ & 0.93 (0.69 to 1.23$)$ & $1.49 *(1.12$ to 1.99$)$ & $1.07(0.73$ to 1.57$)$ \\
\hline $1945-1952$ & 1.09 (0.87 to 1.37$)$ & $1.001(0.75$ to 1.34$)$ & $1.35^{*}(1.01$ to 1.81$)$ & $1.07(0.72$ to 1.57$)$ \\
\hline 1949-1956 & 1.07 (0.85 to 1.36$)$ & $1.14(0.85$ to 1.55$)$ & $1.16(0.85$ to 1.58$)$ & $1.12(0.75$ to 1.69$)$ \\
\hline $1953-1960$ & 1 (REF) & 1 (REF) & 1 (REF) & 1 (REF) \\
\hline \multicolumn{5}{|l|}{ Calendar period } \\
\hline \multicolumn{5}{|c|}{ Calendar period effect from age-period (AP) models } \\
\hline $1987-1990$ & $1.12 *(1.08$ to 1.16$)$ & 0.95 (0.90 to 1.004$)$ & $1.30 *(1.26$ to 1.35$)$ & $1.16 *(1.11$ to 1.20$)$ \\
\hline 1991-1994 & $1.15^{*}(1.11$ to 1.18$)$ & $1.05(0.99$ to 1.10$)$ & $1.28^{*}(1.24$ to 1.33$)$ & $1.21 *(1.16$ to 1.25$)$ \\
\hline 1995-1998 & $1.15 *(1.12$ to 1.19$)$ & $1.08 *(1.02$ to 1.14$)$ & $1.22 *(1.18$ to 1.26$)$ & $1.20 *(1.16$ to 1.25$)$ \\
\hline 1999-2002 & $1.03 *(1.002$ to 1.07$)$ & $1.11 *(1.05$ to 1.17$)$ & $1.10 *(1.06$ to 1.14$)$ & $1.17 *(1.13$ to 1.22$)$ \\
\hline $2003-2006$ & $1.04 *(1.004$ to 1.07$)$ & $1.07 *(1.01$ to 1.12$)$ & $1.05^{*}(1.02$ to 1.09$)$ & $1.11 *(1.07$ to 1.15$)$ \\
\hline $2007-2010$ & 1 (REF) & $1(\mathrm{REF})$ & $1(\mathrm{REF})$ & $1(\mathrm{REF})$ \\
\hline
\end{tabular}

*A statistically significant difference from reference birth cohort (born 1953-1960) or period (year 2007-2010)

lower relative risks for Swedish men born in 1933-1948 and Swedish women born in 1933-1944.

Looking at the APC results from another perspective, it is clear that the individuals currently around the mean age of hip fracture (age 75-86 years; Fig. 2, shaded cohorts) have lower relative risks than expected. This may partly explain the current downturn in hip fracture rates but also has implications for the future as more recently born cohorts (currently younger) have higher relative risks and during the next decade will replace their older counterparts in contribution to the number of hip fractures. Based on this, it is reasonable to expect increasing hip fracture rates in both DK and SE during the upcoming decades, particularly if no future counteracting period effects are seen. Together with the increasing number of old and very old individuals in the population, this may result in a substantially higher annual number of hip fractures in the not so far future.
The fracture probability for an individual at a given time point may be estimated by risk factors such as bone mineral density (BMD), previous fractures, fall risk, comorbidities, and medications as in FRAX®. These prevalent risk factors however depend on both genetics and prior environmental exposure, sometimes very early in life [14]. The fetal programming hypothesis [20] states that abnormal fetal growth is associated with a number of chronic conditions apparent only later in life [21, 22]. Such a pattern has been found also for BMD in SGA (small for gestational age) premature children who develop normal BMD until puberty, but a deficit in the pubertal growth spurt and a low peak bone mass (PBM) [23] and for children with low growth rate and increased hip fracture risk [24]. During the more than 100-year-lived history of the individuals in this analysis, both DK and SE have gradually developed into welfare states and the living 
Fig. 2 Estimation of departure from linearity for birth cohort effects and period effects for ageperiod-cohort (APC) models in Swedish and Danish men and women. Note that, because there is a linear relationship among year of birth, year of hip fracture, and age at hip fracture (i.e., if any two are known, then the third can be calculated), the individual birth cohort effects from the APC model do not necessarily have an interpretation in terms of relative risk (in contrast to the combined period-cohort effects derived from the AC or AP models in Table 3)
Relative Period effects (from APC model

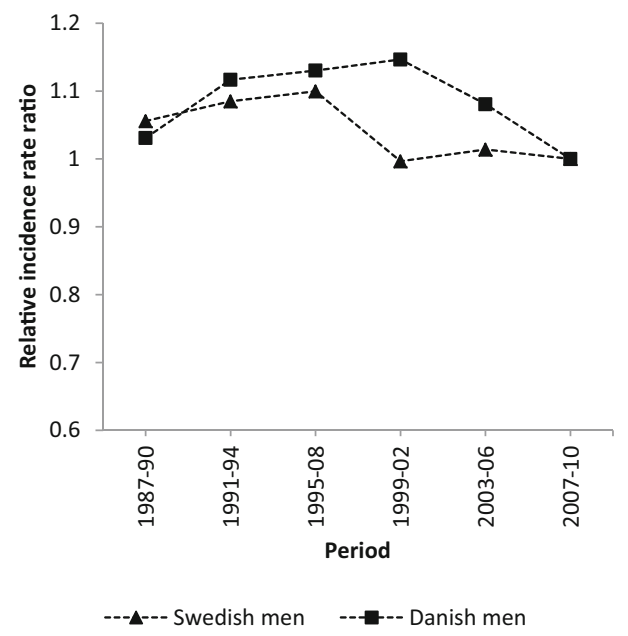

Relative Cohort Effects (from APC model)
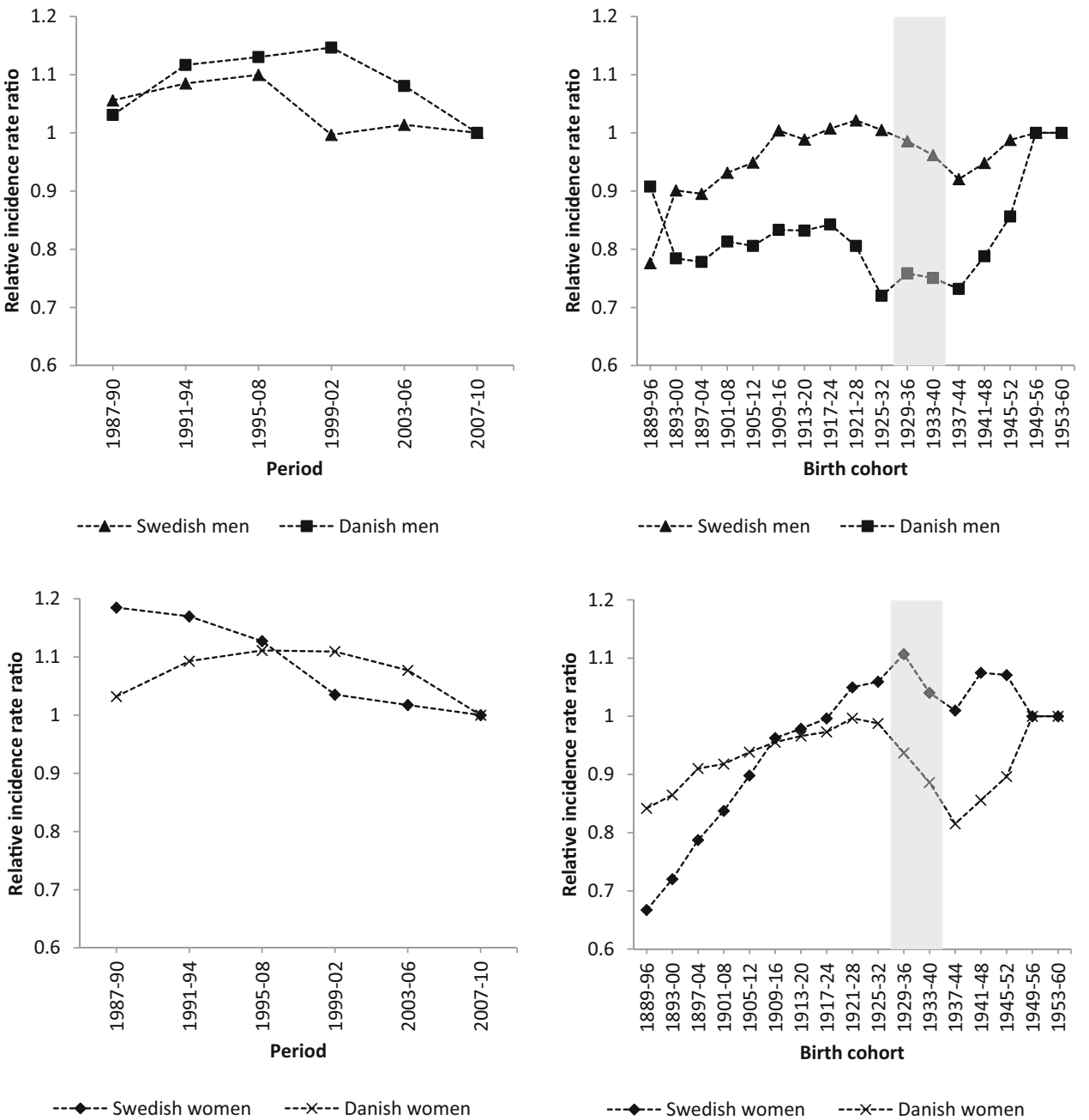

circumstances have undergone major changes. As a general index of better population health, life expectancy at birth has increased.

In many aspects, the population at risk during the later years of the examination period seems healthier in general [25] with a lower prevalence of common diseases [26-28]. It has been suggested that such a healthy population may also, perhaps paradoxically, include more old and frail individuals saved from events which in the past they would not have survived [11]. An increased co-morbidity in US hip fracture patients was registered for the period 1986-2005 consistent with such a mechanism [29].

Theoretically, peak bone mass is a more important factor than bone loss rates - it is estimated that it would take 28 years for a person who lost bone at a rate $1 \mathrm{SD}$ above normal to offset an advantage of having peak bone mass 1 SD above mean [30]. Unfortunately, measurement of BMD has had to wait for the development of appropriate technology and longterm time trends of peak bone mass are therefore not known.
Older, scarce data on time trends of BMD in adult or aged cohorts are available for SE (stable BMD from years 1988/ 1989 to 1998/1999) [31, 32] but none for DK. A recent study from the nearby country of Finland however found increasing BMD in elderly women from year 2002 to 2010 [33], something that previously has been indicated also in the USA (NHANES III 1988/94 to 2005-2008) [34]. In an examination of a non-population-based register of Canadian BMD data in women (from year 1996 to 2006), the decreasing fracture rates were attributed to a secular increase in BMD rather than antiosteoporotic treatment and increase in BMI [35].

Time trends for many measurable indicators important for fracture risk including BMI, BMD, nativity, smoking, exercise, nutrition (including calcium and vitamins), and alcohol consumption are important but also difficult to unravel. In both SE and DK, BMI as well as the proportions of obese and overweight individuals in both women and men have increased, at least to the advent of the new millennium [36, 37], and BMI is now fairly similar in the two countries [38]. 
During the examination period, osteoporosis became officially recognized and defined by the WHO [39], case finding strategies were developed, and pharmacologic treatment became increasingly available. Even though this coincides with the secular decrease in hip fracture rate, the effect on overall hip fracture risk in the population has in ecological data been found to be low (in DK $<5 \%$ ) [6], at least compared to effects originating from the progressive increase in BMI (in DK $+25-$ $50 \%)[6]$.

Trends in HRT prescription may also have influenced fracture risk. The prevalence of HRT use in Sweden decreased from a peak of $36 \%$ in women aged 50-59 years in 1999 to $9 \%$ in 2007 [40]. This rapid change in treatment strategy may have resulted in cohort effects as exemplified in DK by Løkkegaard et al. [41], but would not exert any influence on male fracture risk. Thiazides, beta-blockers, calcium channel blockers, and ACE inhibitors also decrease fragility fracture risk [42,43], and increase in usage over time may thus reduce hip fracture burden.

Many aspects of childbirth may be important for bone health. Birth weight for example seems important for peak BMC [44], even though a Swedish study could not find any association to adult fracture risk in a cohort of women and men born in the year 1915-1929 [45]. Nationwide birth weight data for the birth cohorts in our study are not available for Sweden or Denmark. However, if results from the large Danish Copenhagen School Health Records Register can be extended to the rest of the country, then birth weight has been remarkably stable over the five decades from 1930 to 1984 [21]. Neither DK nor SE has been struck by famine but DK was during WWII occupied while Sweden remained autonomous; the implications are however difficult to appreciate but a study found little impact on anthropometrics in Swedish and Danish children, at least compared to those in Finland and especially Norway [46].

Differences in elderly care between DK and SE may also contribute to disparity in hip fracture risk. In 2007, for example, $22 \%$ of DK individuals $\geq 80$ years were institutionalized compared to only $16 \%$ in Sweden [47, 48], where extensive home care has become targeted more at people with a higher dependency [49]. In Denmark, an offer of preventative home visits to all citizens aged $\geq 75$ years became mandatory in 1996 [50], which may provide better identification of those in need of extended care and institutionalization in DK than SE.

Vitamin D fortification policy has been different in SE and DK. In DK, vitamin D fortification of margarine was mandatory in 1961-1985 and fortification of low-fat milk was permitted between 1972 and 1976. In Sweden, fish liver oil (with high vitamin D content) was recommended to all infants from 1940 onwards, later replaced by drops of vitamins A and D. After World War II, vitamin D was also added to dairy products such as milk and margarine in Sweden at varying levels [51]. Currently, only low-fat dairy and margarine products are fortified. The impact on hip fracture risk of these differences is difficult to appreciate. It should also be mentioned that the prevalence of hip arthroplasty in society may affect the number of hip fracture as a total hip arthroplasty protects from hip fracture. A recent study from the USA found a $5 \%$ prevalence of total hip arthroplasty in individuals aged 80 years with a substantial rise in recent years [52].

Even though APC models are commonly used in, for example, cancer research, only few studies have used the approach for hip fractures trends [7, 9-13]. The results are difficult to compare as they rely on different assumptions and constraints to address the identifiability problem, i.e., to separate the effect of the three entangled factors age, period, and cohort. We chose to use the most recent cohorts as reference as this undoubtedly makes appreciation of recent trends easier. In this, as in our previous study of APC effects of Swedish hip fracture data year 1987 to 2002 [12], we used annual official population statistics in 1-year age classes and not extrapolation of census data as others have [7].

Samelson et al. [10] tabulated hip fracture data from year 1948 to 1995 by birth cohort in a small cohort $(n=5209)$ of men and women born in year 1887 to 1921 . Although the results are noteworthy, the method does not enable separation of the two entangled factors birth cohort and period which substantially blunts the inferences. Evans et al. [9] were the first to use an APC model for hip fracture and used admission data (England and Wales year 1968-1986; 55,261 admissions; born year 1860-1919). Unorthodox age and birth cohort stratification, drift analysis as a single factor, and now outdated birth cohorts and period of examination (not covering recent changes in hip fracture rates) render inferences less interesting today. Langley et al. [11] examined hip fracture discharge data in New Zeeland during an impressive time frame of 1974 2007 in individuals born in 1873-1957. In the same way as we, they allowed sliding in age by period (and vice versa) by utilizing double cohort length to handle the separation problem. Results and inferences are striking but are difficult to set in perspective as they are drawn under the influence of the intrinsic estimator (IE) model, a postulated method for handling the identifiability problem. Jean et al. [13] recently published interesting APC inferences drawn from Canadian discharge data year 1985-2005. The results are difficult to interpret since hospitalization for hip fracture $(n=570,872)$ was the only case selector and the recommended sliding in age during periods (and vice versa) [16-18] was inhibited by use of equal period, age, and birth cohort spans. Alves et al. [7] evaluated APC effects in Portuguese nationwide discharge data year 2000-2008 with hospitalization for hip fracture as case selector $(n=77,083)$. Even though they utilized very narrow age, period, and cohort spans, they, like Jean et al. [13], used equal spans. They did however add a novel approach with generalized additive models (GAM) to identify non-linear effects of age, period, and cohort through spline 
functions. They found a temporal coincidence of a nonsignificantly higher birth cohort hip fracture risk and economically/politically unstable periods.

The strengths of our study include the evaluation of hip fractures in adults (age $\geq 50$ years) in two complete neighboring countries during up to 31 years with central official data on annual population at risk, inclusion of hip fractures from central official registers (used also for reimbursement of care givers), and strict hip fracture definition (through diagnosis records as well as surgical procedure records). The case finding strategy reduces problems with transitions between diagnosis classification systems (prevalent in Sweden from ICD-9 to ICD-10 and in Denmark from ICD-8 to ICD-9) as codes are not fully equivalent between systems and may lead to a classification bias, which we sought to reduce to a minimum by also using surgical procedure codes. Any transition, which may be a period in time when some practitioners are still unused to the new set of codes and local/central administration of registration lags behind, can make a temporary impact in number of events as evident in DK for both men and women in 1995/1996; we addressed this problem by utilizing the 2 year incidence to estimate the number of fractures each year. In the APC model, these years were in the same period (19951998), and the approach was consequently irrelevant for analyses results.

Weaknesses include the inherit limitations of the APC model and in this perspective the relatively short follow-up period of only 24 to 31 years. Because of the linear relationship among age, period, and cohort (i.e., if two factors are known, the third is determined), the period and cohort effects in APC models cannot truly be statistically separated. In the current models, effects of immigration have not been taken into account which may affect the results [53]. Future studies will improve estimates for younger birth cohorts and should include patient-specific data on other important factors should be included, i.e., bone traits, anthropometry, birth weight, apgar score, diseases, medication, etc. With the exception of the Copenhagen area [21], there is no universal source of birth weight data in Denmark for individuals born before 1974, and this population is of course still much too young to provide information on hip fracture outcomes.

\section{Conclusion}

In Denmark and Sweden, earlier trends with decreasing agestandardized hip fracture rates continued during the recent decade except for Swedish men where the rate was stable. The magnitude of the period and cohort effects suggests multiple factors are contributing. Temporal trends as well as gender and national differences may be attributable to disparity in lifestyle as well as changes in hormone-replacement or antiosteoporosis therapy. This should be examined in large international collaborative studies with in-detail patient-specific data. Following from the results of the current analyses, we expect a reversal of the present decline in rates, with increasing hip fracture rates in both Denmark and Sweden during the upcoming decade.

Acknowledgments Financial support was received from ALF, Herman Järnhardts and Greta and Johan Kocks Foundations, Region Skåne FoU, and the Faculty of Medicine at Lund University. The funding sources were not involved in the design, conduct, or interpretation of data or in the writing of the submitted work.

Compliance with ethical standards The study, which utilized only anonymized official registry data, was approved by Statistics Denmark (project reference 703857) and the ethics committee at Lund University, Sweden (2012/394).

Conflicts of interest $\mathrm{BR}, \mathrm{JB}$, and $\mathrm{CC}$ have no potential conflicts of interest. BA has received research grants from or served as an investigator in studies for Novartis, Nycomed/Takeda, NPS Pharmaceuticals, and Amgen and has in the past served as a national advisory board member for Nycomed/Takeda, Merck, and Amgen, and received speakers fees from Nycomed/Takeda, Amgen, Merck, and Eli Lilly.

Open Access This article is distributed under the terms of the Creative Commons Attribution-NonCommercial 4.0 International License (http:// creativecommons.org/licenses/by-nc/4.0/), which permits any noncommercial use, distribution, and reproduction in any medium, provided you give appropriate credit to the original author(s) and the source, provide a link to the Creative Commons license, and indicate if changes were made.

\section{References}

1. Cauley JA, Chalhoub D, Kassem AM, Fuleihan Gel H (2014) Geographic and ethnic disparities in osteoporotic fractures. Nat Rev Endocrinol 10(6):338-351. doi:10.1038/nrendo.2014.51

2. Dhanwal DK, Dennison EM, Harvey NC, Cooper C (2011) Epidemiology of hip fracture: worldwide geographic variation. Indian J Orthop 45(1):15-22. doi:10.4103/0019-5413.73656

3. Rosengren BEKMK, Petterson I, Englund M (2014) The 21st century landscape of adult fractures - cohort study of a complete adult regional population. J Bone Min Res 30(3):535-542

4. Kannus P, Niemi S, Parkkari J, Palvanen M, Vuori I, Jarvinen M (2006) Nationwide decline in incidence of hip fracture. J Bone Miner Res 21(12):1836-1838

5. Rosengren BE, Karlsson MK (2014) The annual number of hip fractures in Sweden will double from year 2002 to 2050. Acta Orthop. doi:10.3109/17453674.2014.916491

6. Abrahamsen B, Vestergaard P (2010) Declining incidence of hip fractures and the extent of use of anti-osteoporotic therapy in Denmark 1997-2006. Osteoporos Int 21(3):373-380. doi:10.1007/s00198-009-0957-3

7. Alves SM, Castiglione D, Oliveira CM, de Sousa B, Pina MF (2014) Age-period-cohort effects in the incidence of hip fractures: political and economic events are coincident with changes in risk. Osteoporos Int 25(2):711-720. doi:10.1007/s00198-013-2483-6

8. Leslie WD, O'Donnell S, Jean S, Lagace C, Walsh P, Bancej C, Morin S, Hanley DA, Papaioannou A (2009) 
Trends in hip fracture rates in Canada. JAMA 302(8):883889. doi:10.1001/jama.2009.1231

9. Evans JG, Seagroatt V, Goldacre MJ (1997) Secular trends in proximal femoral fracture, Oxford record linkage study area and England 1968-86. J Epidemiol Community Health 51(4):424-429

10. Samelson EJ, Zhang Y, Kiel DP, Hannan MT, Felson DT (2002) Effect of birth cohort on risk of hip fracture: age-specific incidence rates in the Framingham Study. Am J Public Health 92(5):858-862

11. Langley J, Samaranayaka A, Davie G, Campbell AJ (2011) Age, cohort and period effects on hip fracture incidence: analysis and predictions from New Zealand data 1974-2007. Osteoporos Int 22(1):105-111. doi:10.1007/s00198-010-1205-6

12. Rosengren BE, Ahlborg HG, Mellstrom D, Nilsson JA, Bjork J, Karlsson MK (2012) Secular trends in Swedish hip fractures 19872002: birth cohort and period effects. Epidemiology 23(4):623630. doi:10.1097/EDE.0b013e318256982a

13. Jean S, O'Donnell S, Lagace C, Walsh P, Bancej C, Brown JP, Morin S, Papaioannou A, Jaglal SB, Leslie WD, Osteoporosis Surveillance Expert Working G (2013) Trends in hip fracture rates in Canada: an age-period-cohort analysis. J Bone Miner Res 28(6): 1283-1289. doi:10.1002/jbmr.1863

14. Cooper C, Harvey N, Cole Z, Hanson M, Dennison E (2009) Developmental origins of osteoporosis: the role of maternal nutrition. Adv Exp Med Biol 646:31-39. doi:10.1007/978-1-4020-9173-5_3

15. Cooper C, Cole ZA, Holroyd CR, Earl SC, Harvey NC, Dennison EM, Melton LJ, Cummings SR, Kanis JA, Epidemiology ICWGoF (2011) Secular trends in the incidence of hip and other osteoporotic fractures. Osteoporos Int 22(5):1277-1288. doi:10.1007/s00198011-1601-6

16. Clayton D, Schifflers E (1987) Models for temporal variation in cancer rates. I: age-period and age-cohort models. Stat Med 6(4): 449-467

17. Clayton D, Schifflers E (1987) Models for temporal variation in cancer rates. II: age-period-cohort models. Stat Med 6(4):469-481

18. Holford TR (1991) Understanding the effects of age, period, and cohort on incidence and mortality rates. Annu Rev Public Health 12:425-457. doi:10.1146/annurev.pu.12.050191.002233

19. Tarone RE, Chu KC (1996) Evaluation of birth cohort patterns in population disease rates. Am J Epidemiol 143(1):85-91

20. Barker DJ (2000) In utero programming of cardiovascular disease. Theriogenology 53(2):555-574

21. Baker JL, Olsen LW, Sorensen TI (2008) Weight at birth and allcause mortality in adulthood. Epidemiology 19(2):197-203. doi:10.1097/EDE.0b013e31816339c6

22. Gluckman PD, Hanson MA, Cooper C, Thornburg KL (2008) Effect of in utero and early-life conditions on adult health and disease. N Engl J Med 359(1):61-73. doi:10.1056 /NEJMra0708473

23. Buttazzoni C, Rosengren B, Tveit M, Landin L, Nilsson JA, Karlsson M (2015) Preterm children born small for gestational age are at risk for low adult bone mass. Calcif Tissue Int 98. doi:10.1007/s00223-015-0069-3

24. Cooper C, Eriksson JG, Forsen T, Osmond C, Tuomilehto J, Barker DJ (2001) Maternal height, childhood growth and risk of hip fracture in later life: a longitudinal study. Osteoporos Int 12(8):623629. doi:10.1007/s001980170061

25. Svanborg A (2007) The health of the elderly population: results from longitudinal studies with age-cohort comparisons. In: Ciba Foundation symposium 134 -research and the ageing population. Wiley, pp 3-16. doi:10.1002/9780470513583.ch2

26. Karampampa K, Andersson T, Drefahl S, Ahlbom A, Modig K (2014) Does improved survival lead to a more fragile population: time trends in second and third hospital admissions among men and women above the age of 60 in Sweden. PLoS One 9(6):e99034. doi:10.1371/journal.pone.0099034
27. Modig K, Andersson T, Drefahl S, Ahlbom A (2013) Age-specific trends in morbidity, mortality and case-fatality from cardiovascular disease, myocardial infarction and stroke in advanced age: evaluation in the Swedish population. PLoS One 8(5):e64928. doi:10.1371/journal.pone.0064928

28. Berg J, Bjorck L, Lappas G, O’Flaherty M, Capewell S, Rosengren A (2014) Continuing decrease in coronary heart disease mortality in Sweden. BMC Cardiovasc Disord 14:9. doi:10.1186/1471-2261-14-9

29. Brauer CA, Coca-Perraillon M, Cutler DM, Rosen AB (2009) Incidence and mortality of hip fractures in the United States. JAMA 302(14):1573-1579. doi:10.1001/jama.2009.1462

30. Hui SL, Slemenda CW, Johnston CC Jr (1990) The contribution of bone loss to postmenopausal osteoporosis. Osteoporos Int 1(1):30-34

31. Rosengren BE, Ahlborg HG, Gardsell P, Sernbo I, Daly RM, Nilsson JA, Karlsson MK (2010) Bone mineral density and incidence of hip fracture in Swedish urban and rural women 1987-2002. Acta Orthop 81(4):453-459. doi:10.3109/17453674.2010.492762

32. Rosengren BE, Ahlborg HG, Gardsell P, Sernbo I, Nilsson JA, Daly RM, Karlsson MK (2012) Forearm bone mineral density and incidence of hip fractures in Swedish urban and rural men 1987-2002. Scand J Public Health 40(1):102-108. doi:10.1177/1403494811425604

33. Uusi-Rasi K, Karinkanta S, Heinonen A, Sievanen H (2013) Improved femoral neck BMD in older Finnish women between 2002 and 2010. Maturitas 75(3):241-245. doi:10.1016/j. maturitas.2013.04.001

34. Looker AC, Melton LJ 3rd, Borrud LG, Shepherd JA (2012) Changes in femur neck bone density in US adults between 1988-1994 and 20052008: demographic patterns and possible determinants. Osteoporos Int 23(2):771-780. doi:10.1007/s00198-011-1623-0

35. Leslie WD, Lix LM, Yogendran MS, Morin SN, Metge CJ, Majumdar SR (2014) Temporal trends in obesity, osteoporosis treatment, bone mineral density, and fracture rates: a populationbased historical cohort study. J Bone Miner Res 29(4):952-959. doi:10.1002/jbmr.2099

36. Finucane MM, Stevens GA, Cowan MJ, Danaei G, Lin JK, Paciorek CJ, Singh GM, Gutierrez HR, Lu Y, Bahalim AN, Farzadfar F, Riley LM, Ezzati M, Global Burden of Metabolic Risk Factors of Chronic Diseases Collaborating G (2011) National, regional, and global trends in body-mass index since 1980: systematic analysis of health examination surveys and epidemiological studies with 960 countryyears and 9.1 million participants. Lancet 377(9765):557-567. doi:10.1016/S0140-6736(10)62037-5

37. Dey DK, Rothenberg E, Sundh V, Bosaeus I, Steen B (2001) Height and body weight in elderly adults: a 21-year population study on secular trends and related factors in 70-year-olds. J Gerontol A Biol Sci Med Sci 56(12):M780-M784

38. Svedbom A, Hernlund E, Ivergard M, Compston J, Cooper C, Stenmark J, McCloskey EV, Jonsson B, Kanis JA (2013) Osteoporosis in the European Union: a compendium of countryspecific reports. Arch Osteoporos 8(1-2):137. doi:10.1007/s11657013-0137-0

39. WHO (1994) Assessment of fracture risk and its application to screening for postmenopausal osteoporosis. Report of a WHO Study Group. World Health Organ Tech Rep Ser 843:1-129

40. Lambe M, Wigertz A, Holmqvist M, Adolfsson J, Bardage C, Fornander T, Karlsson P, Odlind V, Persson I, Ahlgren J, Bergkvist L (2010) Reductions in use of hormone replacement therapy: effects on Swedish breast cancer incidence trends only seen after several years. Breast Cancer Res Treat 121(3):679-683. doi:10.1007/s10549-009-0615-7

41. Lokkegaard E, Lidegaard O, Moller LN, Agger C, Andreasen AH, Jorgensen T (2007) Hormone replacement therapy in Denmark, 1995-2004. Acta Obstet Gynecol Scand 86(11):1342-1351. doi:10.1080/00016340701505523

42. Wiens M, Etminan M, Gill SS, Takkouche B (2006) Effects of antihypertensive drug treatments on fracture outcomes: a meta- 
analysis of observational studies. J Intern Med 260(4):350-362. doi:10.1111/j.1365-2796.2006.01695.x

43. Rejnmark L, Vestergaard P, Mosekilde L (2006) Treatment with beta-blockers, ACE inhibitors, and calcium-channel blockers is associated with a reduced fracture risk: a nationwide case-control study. J Hypertens 24(3):581-589. doi:10.1097/01.hjh.0000203845.26690.cb

44. Callreus M, McGuigan F, Akesson K (2013) Birth weight is more important for peak bone mineral content than for bone density: the PEAK-25 study of 1,061 young adult women. Osteoporos Int 24(4):1347-1355. doi:10.1007/s00198-012-2077-8

45. Byberg L, Michaelsson K, Goodman A, Zethelius B, Koupil I (2014) Birth weight is not associated with risk of fracture: results from two Swedish cohort studies. J Bone Miner Res 29(10):21522160. doi:10.1002/jbmr.2246

46. Angell-Andersen E, Tretli S, Bjerknes R, Forsen T, Sorensen TI, Eriksson JG, Rasanen L, Grotmol T (2004) The association between nutritional conditions during World War II and childhood anthropometric variables in the Nordic countries. Ann Hum Biol 31(3):342-355. doi:10.1080/03014460410001685304

47. Schultz E (2010) The long-term care system for the elederly in Denmark-ENEPRI research report no. 73
48. Fukushima N, Adami J, Palme M (2010) The long-term care system for the elederly in Sweden-ENEPRI research report no. 89

49. Genet N, Boerma WGW, Kringos DS, Bouman A, Francke AL, Fagerström C, Melchiorre MG, Greco C, Devillé W (2011) Home care in Europe: a systematic literature review. BMC Health Serv Res 11:207-207. doi:10.1186/1472-696311-207

50. Campbell L, Wagner L (2009) Prevention and rehabilitaion in the long-term care system in Denmark. Interlinks EU report

51. Becker W (2000) Berikad mjölk - viktig d-vitaminkälla för svenska barn. Vår föda 52(4):23-24

52. Maradit Kremers H, Larson DR, Crowson CS, Kremers WK, Washington RE, Steiner CA, Jiranek WA, Berry DJ (2015) Prevalence of total hip and knee replacement in the United States. J Bone Joint Surg Am 97(17):1386-1397. doi:10.2106/jbjs. n.01141

53. Albin B, Hjelm K, Elmstahl S (2010) Lower prevalence of hip fractures in foreign-born individuals than in Swedish-born individuals during the period 1987-1999. BMC Musculoskelet Disord 11: 203. doi:10.1186/1471-2474-11-203 